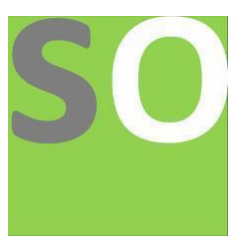

Article title: Annual Income Contribution of Wood fuel production from Small-scale Plantation Forest Experience from Farmers in Fagta Lekoma, Awi zone, Amhara, Ethiopia

Authors: MENGISTU MITKU ALEMU[1]

Affiliations: Ethiopian Environment and Forest research Institute[1]

Orcid ids: 0000-0002-5747-7139[1]

Contact e-mail: mitkualemu12@gmail.com

License information: This work has been published open access under Creative Commons Attribution License http://creativecommons.org/licenses/by/4.0/, which permits unrestricted use, distribution, and reproduction in any medium, provided the original work is properly cited. Conditions, terms of use and publishing policy can be found at https://www.scienceopen.com/.

Preprint statement: This article is a preprint and has not been peer-reviewed, under consideration and submitted to ScienceOpen Preprints for open peer review.

Funder: No funder

DOI: 10.14293/S2199-1006.1.SOR-.PPZDQBA.v1

Preprint first posted online: 03 September 2020

Keywords: Households livelihood options; small-scale plantation forest; means of household income; Sustainable development 


\title{
Annual Income Contribution of Wood fuel production from Small-scale Plantation Forest Experience from Farmers in Fagta Lekoma, Awi zone, Amhara, Ethiopia
}

\section{Mitku Alemu Mengistu ${ }^{1, *}$}

1 Ethiopian Environment and Forest Research Institute, P.O. Box 24536 code 1000 Addis Ababa. mitkualemu12@gmail.com

* Correspondence: mitkualemu12@gmail.com; Tel.: Tel +251921282708

\begin{abstract}
This study aims to examine the annual income contribution of wood fuel production from small - scale plantation forestry in Fagta Lekoma district of Amhara region, Ethiopia. Household surveys were conducted by following the snowball-sampling technique. The data analyzed by using STATA software and multiple linear regression model also employed to evaluate the contribution of wood fuel annual income from the total annual income of the households. About 9000 Ethiopian Birr (ETB) household income comes from charcoal selling which is the highest average annual income. The result of multiple linear regression analysis indicates that an increase in one unit (ETB) income from charcoal making leads to an increase in total annual income by 0.972 units (ETB). Annual income contribution of wood fuel production is the largest amount of income recorded followed by annual income from crop production. Plantation forestry plays a significant role not only economically but also by the provision of alternative livelihood options for households. Plantation forestry used as a means of soil reclamation as well as means of households' income. Inaction and implementation of policies supporting plantation forestry sustain rural livelihood by increasing their adaptive potential for shock and stress by creating alternative means of livelihood.
\end{abstract}

Keywords: Households livelihood options; small-scale plantation forest; means of household income; Sustainable development.

\section{Introduction}

Small scale plantation forests play a significant role in contributing to household income as well as poverty reduction for community level (Cuong, Chinh, Zhang, \& Xie, 2020). Smallscale plantation forests for commercial wood fuel production play a significant role in supporting the livelihoods of farmers. Despite the potential of wood fuel contribution for households income generation limited study was conducted. Thus, this study aims to quantify the role of wood fuel production from a small-scale plantation in the Awi zone of Fagta Lecoma district, which found in the Amhara region Ethiopia with the rapid expansion of Acacia decurrence and eucalyptus plantation at an alarming rate, especially in recent years.

The contribution of wood fuel production is not only restricted to the provision of energy sources but also provides important income generation options for rural farmers in sub - Saharan African country which is true for Ethiopian farmers who live in the northern highland of the country (Zulu \& Richardson, 2013). Plantation of trees increasing at an alarming rate worldwide for instance from 1990 to 2000 plantation forest land estimated to be 143.4 million hectares which have a drastic change in terms of expansion estimated from 1980 to 1990 which is only about 25.8 million hectares. The expansion of plantation associated with the cause of social conflicts (Schirmer, 2007). Eucalyptus is not only the 
most planted tree species in the world but also it is the dominant plantation tree in east Africa by covering a total area of 524 million hectares of land (FAO, 2009). Eucalyptus is mostly preferred species by Ethiopian farmers due to its nature of fast growth, relatively easy management, and the ability to coppice (Jenbere, Lemenih, \& Kassa, 2012). More than 92000 hectares of eucalyptus plantation were recorded of which about $67 \%$ planted by smallholder farmers (Kebede Gizachew, 2017).

The expansion of smallholder's commercial plantation needs trade-off agricultural crop production land (Abiyu, Teketay, Gratzer, \& Shete, 2016). The production of small scale plantation by farmers fuelled not only by demand for wood fuel from nearby cities but also to reclaim degrade soil and to raise soil fertility which upturns the yield of crop produced (Molla \& Linger, 2017) especially acacia decurrence trees Fagta Lakoma district, Awi zone North-western Ethiopia. Planting of Eucalyptus tree also preferred by a farmer than the production of the crop in the study area due to numerous reasons such as low productivity of crop aggravated by fast-growing demand for wood and wood products as well as fast growth characteristics of the species (Aklilu, Bekele, Merkineh, \& Barana, 2019).

Despite the argument of the adverse impact of eucalyptus species on the ecological balance and negative allopathic impact farmers intensively skewed to planting eucalyptus trees on their farmland which creates disputes with agricultural extension agents and local experts (Aklilu et al., 2019). The dispute aggravated by the expansion of tree plantation on productive cropland of which is strongly unsupported by local agricultural experts. The expansion of tree planting on cropland creates a conflict of interest between cropland and tree plantation land (Ayana \& Lejissa, 2018) so this study tries to seek solutions for harmonizing conflict of interest between farmers and development agents by providing scientific information.

In Ethiopia agricultural land degradation is a series problem that reduces crop production (Adimassu, Kessler, \& Hengsdijk, 2012). Loss of cropland productivity push farmers to reclaim their farmland while to bust agricultural production form their land thus farmers decide to expand Acacia decurrence planation to their cropland which is the main source of conflict and disagreement between farmers and local agricultural expert in the study area. Forest degradation and intensive farming aggravate the salinity of agricultural land in the study site afforestation and small scale commercial plantation expansion on farmland not only increase soil fertility but also diversify means of livelihood. On the other hand, a study conducted in Arisi Negele indicates that more than $11 \%$ of farmers convert their cropland into eucalypt plantation (Jenbere et al., 2012) and states planation woodlots increase at the expense of cropland. To resolve the disputes between farmers and agricultural experts as well as to suggest appropriate innervation conducting this study plays a significant role.

\section{Methodology}

To examine the role of plantation forest in reducing poverty purposive sampling technique used. Wood fuel producers were identified with local development agents and listed purposively to select 99 respondents from 3 potential Kebeles by following snowballsampling techniques the study site was selected based on its potential of wood fuel production from small scale commercial plantation. The collected survey data subjected to statistical analysis by using STATA 14 statistical software. To evaluate the economic contribution of wood fuel production for annual income form plantation for a household a multiple regression was used and the result discussed by using descriptive statics such as 
frequency, percentage mean and standard deviation the result presented by using tables and graphs.

\subsection{Description of the study site}

The study was conducted in the Fagta Lekoma district, which is characterized, by the expansion of small-scale commercial plantation wood lot. The district found 1800 to 2800 m.a.I range of altitudinal variation about $19.5 \%$ of the district covered by forest the mean annual rainfall ranges between $1500 \mathrm{~mm}$ to $2500 \mathrm{~mm}$ and the mean annual temperature is between $12{ }^{\circ} \mathrm{C}$ to $22^{\circ} \mathrm{C}$ which makes the district suitable for tree plantation (Molla \& Linger, 2017).

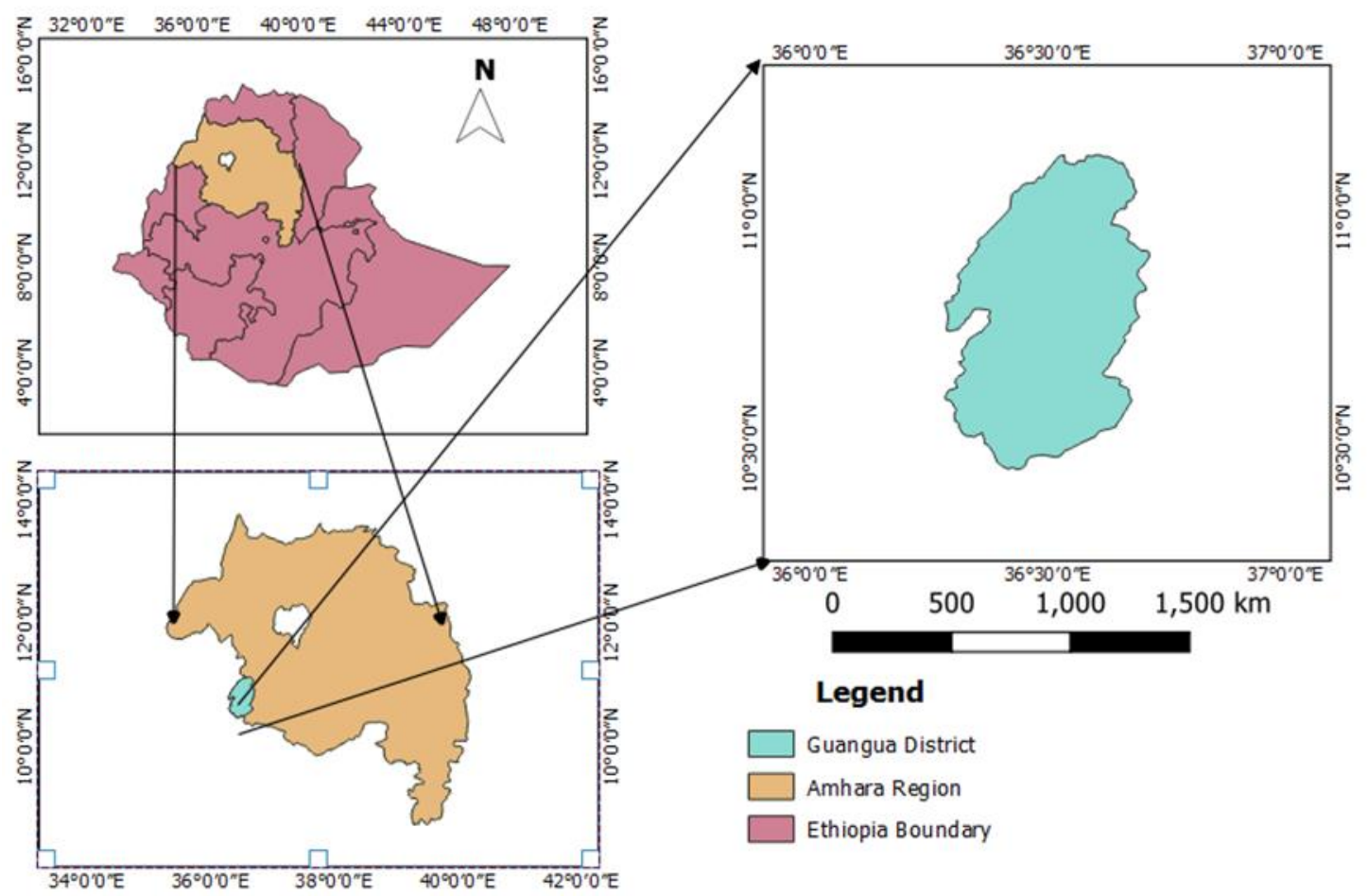

Figure 1. Map of the study area

\subsection{Data collection and sampling methods}

To evaluate the contribution of annual income from wood fuel production a combination of purposive and snowball sampling methods was carried out. Based on the potential of wood fuel production three kebeles were selected then following referral sampling method 99 households were selected.

\subsection{Model specification and variable description}

A multiple linear regression model was used to evaluate the contribution of wood fuel production income for the total annual income of households' and the model specified as follows

$$
\mathrm{TAl}=B_{0}+B_{1}\left|\mathrm{CHM}+B_{2}\right| \mathrm{FWS}+B_{3}\left|\mathrm{ACS}+B_{4}\right| \mathrm{LVS}+B_{5} I \mathrm{NTFP}+\mathrm{U}
$$




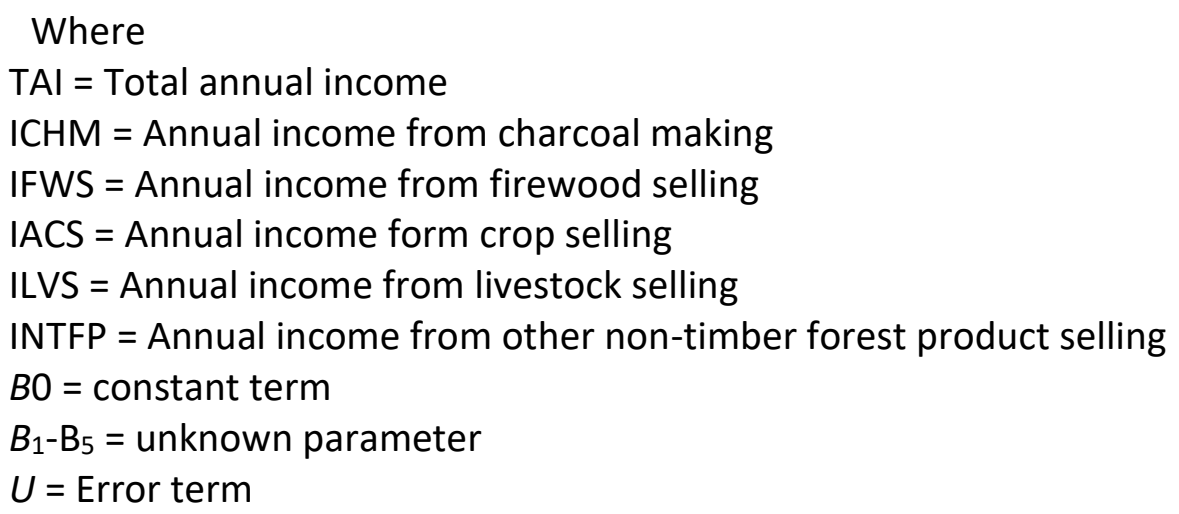

\section{Results}

\subsection{Summary of respondents socio-economic status}

Description of target households was described by using descriptive statistics from a total of 99 households about 93 respondents were male and the rest 6 respondents were female. 89 respondents were married 8 and 2 respondents were unmarried and windowed respectively.

Table 1. Description of respondents' socioeconomic status

\begin{tabular}{|c|c|c|c|}
\hline categorical variables & frequency & $\max$ & $\min$ \\
\hline \multicolumn{4}{|l|}{ sex of respondents } \\
\hline male & 93 & & \\
\hline female & 6 & & \\
\hline \multicolumn{4}{|l|}{ marital status } \\
\hline married & 89 & & \\
\hline unmarried & 8 & & \\
\hline windowed & 2 & & \\
\hline \multicolumn{4}{|l|}{ wealth status } \\
\hline rich & 1 & & \\
\hline medium & 66 & & \\
\hline poor & 32 & & \\
\hline \multicolumn{4}{|l|}{ Education status } \\
\hline Illiterate & 33 & & \\
\hline primary education & 35 & & \\
\hline secondary education & 26 & & \\
\hline Bachelor degree & 1 & & \\
\hline Informal education & 4 & & \\
\hline \multicolumn{4}{|l|}{ Continues variables } \\
\hline Age of respondents & & 19 & 87 \\
\hline Landholding in ha & & 0 & 6 \\
\hline family size & & 1 & 11 \\
\hline Permanent residence in years & & 1 & 5 \\
\hline Experience in wood fuel production & & 1 & 5 \\
\hline
\end{tabular}


The wealth status of the respondents indicates that about 66 respondents categorized as rich while 32 respondents as medium wealth class only 1 respondent found in rich class. The age of respondents rages from 19 to 87 years old, which encompass a wide range of age class. Land size ownership varied from 0 to 6 ha. The minimum family size was about 1 while 6 people per household were the maximum family size. The experience of respondents in the year also other variables. The minimum years of experience were about 1 year whereas the maximum year of experience was about 5 year

\subsection{Estimation of wood fuel contribution for households annual income}

The contribution of wood fuel production for annual income estimated by using multiple linear regression and the result discussed as follow. The result of multiple linear regression analysis indicates that an increase in one unit (ETB) income from charcoal making leads to an increase in total annual income by 0.972 unit (ETB).

Table 2. Contribution of wood fuel production from the small-scale plantation for household income

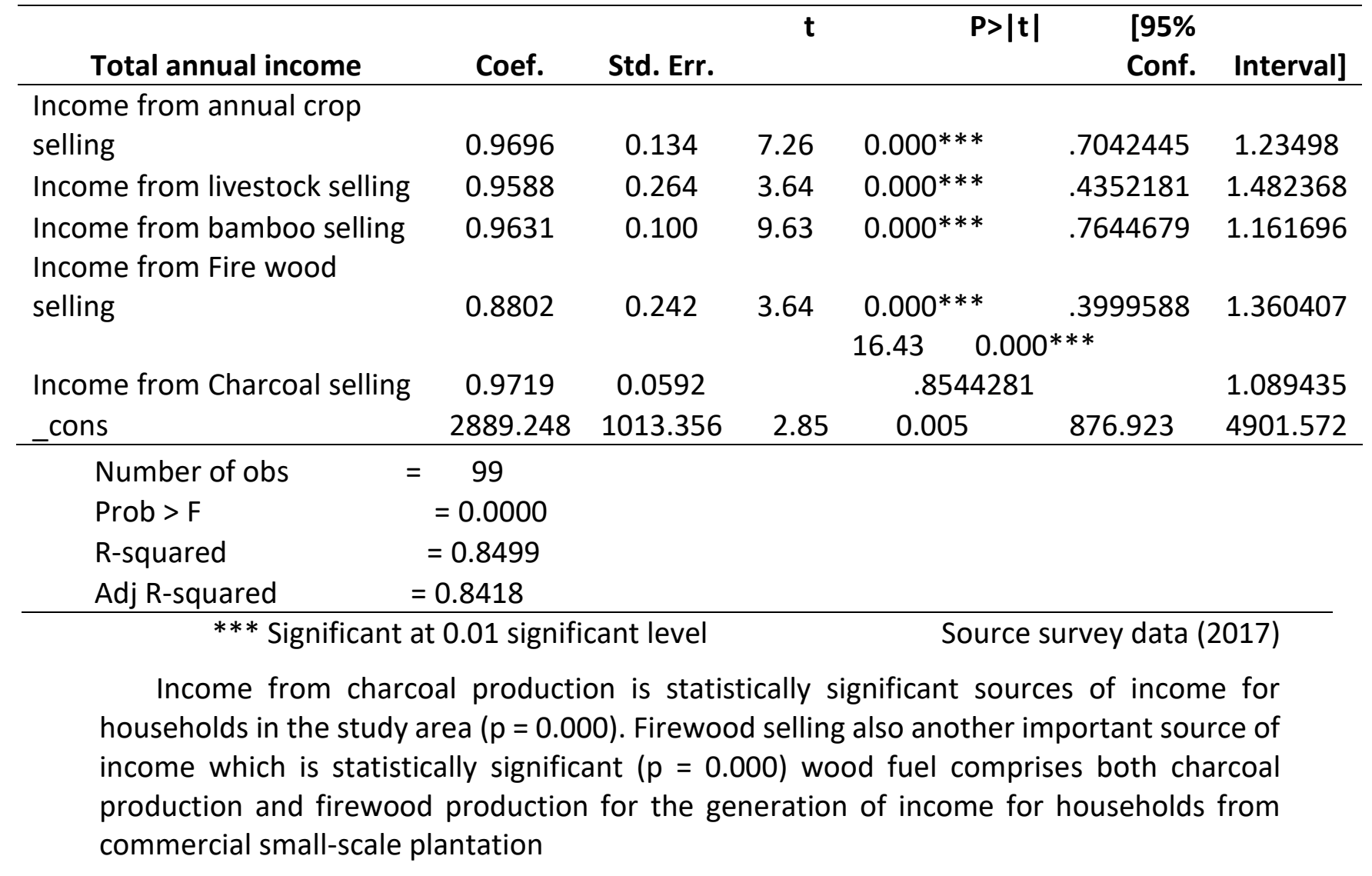

\subsection{Comparison of livelihood contribution for household annual income}

Annual income contribution of wood fuel production is the largest amount of income recorded followed by annual income from crop production while the thread rank occupied by income from bamboo livestock and firewood play important role in generating annual income. The average annual income of households indicates that about 9000 Ethiopian Birr (ETB) comes from charcoal selling which is the highest average annual income. Cereal crop selling contributes about 3000 ETB, selling of bamboo and livestock generate 2000 ETB and 1000 ETB respectively. 


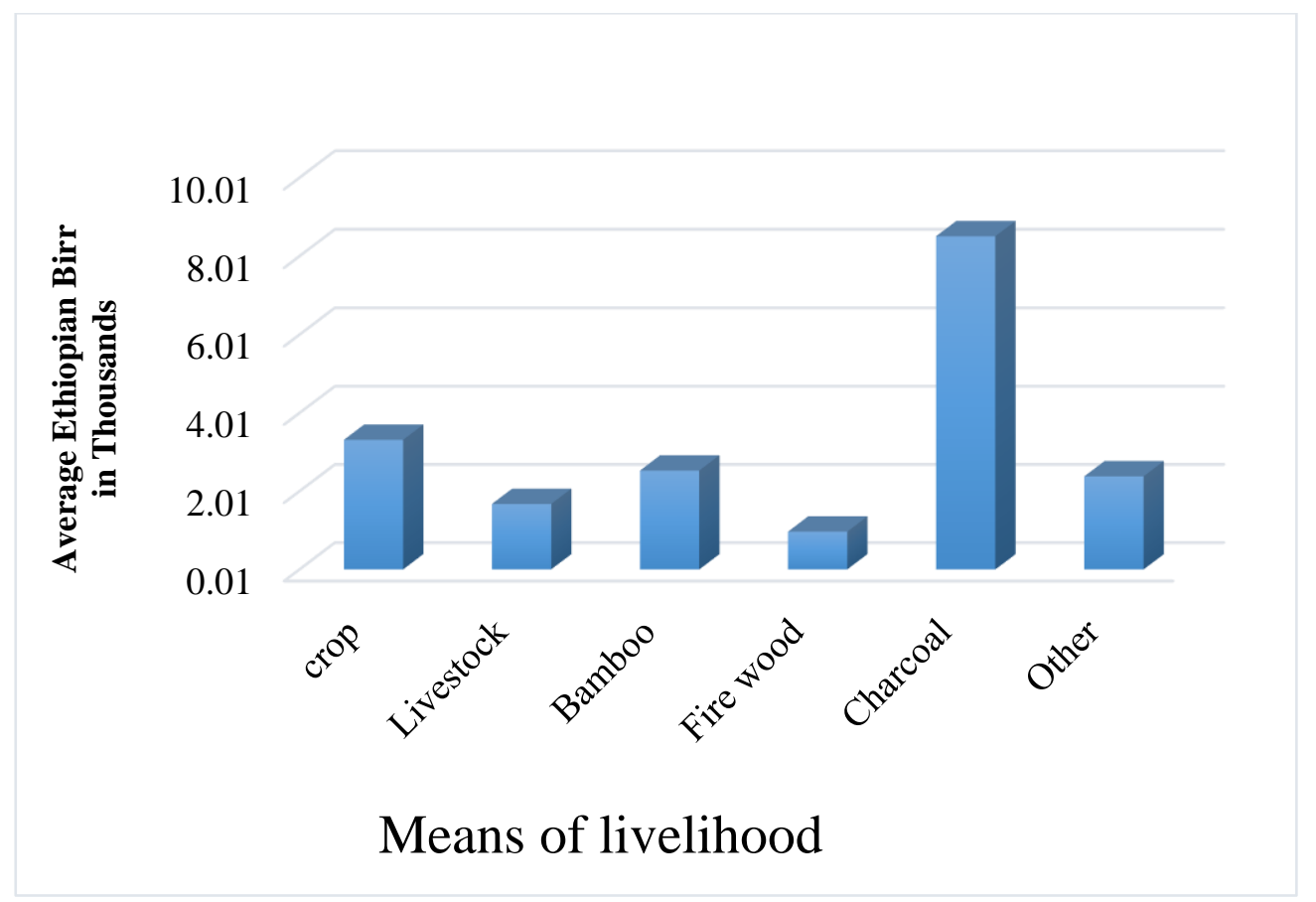

Figure 2. Household income contribution from different livelihood option

\subsection{Order of livelihood contribution for household annual income}

Charcoal making is the most important source of livelihood income from small-scale plantation forests. The second most important source of income for households from their plantation is firewood selling while bamboo is the third important plantation forest means of income. The order of importance for the contribution of plantation forest for households' livelihood indicates Charcoal production and selling account major annual household income. Plantation forests account for a significant portion of livelihood means in the study area.

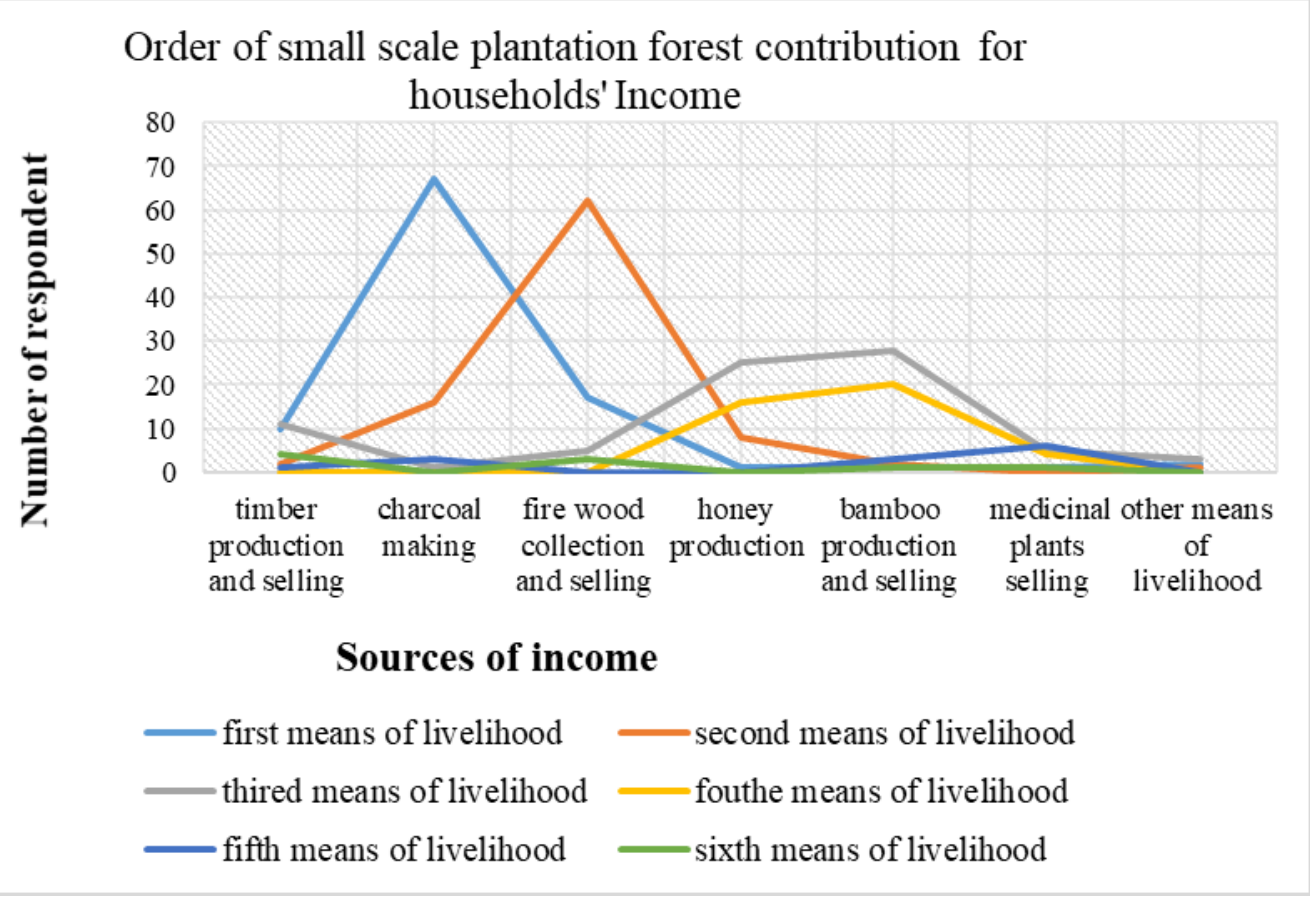

Figure 3. Order of small-scale plantation contribution for annual household income 


\section{Discussion}

Generally the role of small-scale plantation forest for households' income significantly important in reducing poverty. Besides reclamation potentials of forest plantation, it diversifies livelihood options for farmers to increase resilience from risk and shock caused by climate change. Soil salinity is a major problem challenging crop productivity thus farmers innovate acacia decurrence to reclaim their farmland intercropping also the farming system used by farmers to boost land productivities. Even if a large number of farmers establish their livelihood on crop production but the average annual income from wood fuel production and selling is larger than average annual income form crop production that shows small-scale plantation forestry play important role in reducing poverty. Promoting specialization in the production of wood fuel specifically and plantation forestry at large helps to build green economy development.

\section{Conclusions}

Due to the misconception of local agricultural experts about the economic contribution of plantation forestry the disfavor farmers to expend tree plantation on their farmland. The study also found that charcoal production and firewood production for markets provide higher average annual income for households than other non-crop means of income. Modernizing the process of wood fuel production system reduces environmental pollution while decreasing the risk of wood fuel production More study needed to reduce the damage due to disease and pest in the planation sector while diversifying the number of fastgrowing tree species (Oladeji, Ologunwa, \& Tonkollie, 2018). Households engage in crop production, wood fuel production, livestock production, bamboo production, and formal employment as their sources of livelihood in the study area. Participation in plantation forestry diversify means of household income while creating shock resilient society.

Funding: "This research received no external funding"

Acknowledgments: I would like to thank my supervisor for his fruit full supervision and valuable comments as well as his generous contribution financial support for publication fee.

Conflicts of Interest: "The authors declare no conflict of interest." Also, "The funders had no role in the design of the study; in the collection, analyses, or interpretation of data; in the writing of the manuscript, or in the decision to publish the results".

\section{References}

[1] Abiyu, A., Teketay, D., Gratzer, G., \& Shete, M. (2016). Tree Planting by Smallholder Farmers in the Upper Catchment of Lake Tana Watershed, Northwest Ethiopia. Small-Scale Forestry, 15(2), 199-212. https://doi.org/10.1007/s11842-015-9317-7

[2] Adimassu, Z., Kessler, A., \& Hengsdijk, H. (2012). Exploring determinants of farmers' investments in land management in the Central Rift Valley of Ethiopia. Applied Geography, 35(1-2), 191-198. https://doi.org/10.1016/j.apgeog.2012.07.004

[3] Aklilu, B. M., Bekele, L., Merkineh, M. M., \& Barana. (2019). Is the expansion of Eucalyptus tree a curse or an opportunity? Implications from a dispute on the trees ecological and economic impact in Ethiopia: A review. Journal of Ecology and The Natural Environment, 11(6), 75-83. https://doi.org/10.5897/jene2019.0765

[4] Ayana, A. N., \& Lejissa, L. T. (2018). Comparative Economic Analysis of Three 
Competing Land Use Types in Southern Ethiopia: Tools for Informed DecisionMaking on Land Use Choices. Journal of Economics and Sustainable Development, 9(1), 37-45.

[5] Cuong, T., Chinh, T. T. Q., Zhang, Y., \& Xie, Y. (2020). Economic performance of forest plantations in Vietnam: Eucalyptus, Acacia mangium, and Manglietia conifera. Forests, 11(3). https://doi.org/10.3390/f11030284

[6] FAO. (2009). Eucalyptus in east Africa: the socioeconomic and environmental issues. FAO Sub-Regional Office Eastern Africa, Addis Ababa, (March), 40.

[7] Jenbere, D., Lemenih, M., \& Kassa, H. (2012). Expansion of Eucalypt Farm Forestry and Its Determinants in Arsi Negelle District, South Central Ethiopia. Small-Scale Forestry, 11(3), 389-405. https://doi.org/10.1007/s11842-011-9191-x

[8] Kebede Gizachew. (2017). Expansion of Eucalypt Woodlot and Its Factors in Cheha District, Southern Ethiopia. In World Sscientific News (Vol. 66). Retrieved from www.worldscientificnews.com

[9] Molla, A., \& Linger, E. (2017). Effects of Acacia decurrens (Green wattle ) Tree on selected Soil Physico-chemical properties North- western Ethiopia. Research Journal of Agriculture and Environmental Management, 6(5)(May 2018), 095-103.

[10] Oladeji, S. O., Ologunwa, O. P., \& Tonkollie, B. T. (2018). Socio-economic Impact of Traditional Technology of Charcoal Production in Kpaai District-Bong County Liberia. Environmental Management and Sustainable Development, 7(2), 86. https://doi.org/10.5296/emsd.v7i2.11770

[11] Schirmer, J. (2007). Plantations and social conflict: exploring the differences between small-scale and large-scale plantation forestry. Small-Scale Forestry, 6(1), 19-33. https://doi.org/10.1007/s11842-007-9001-7

[12] Zulu, L. C., \& Richardson, R. B. (2013). Charcoal, livelihoods, and poverty reduction: Evidence from sub-Saharan Africa. Energy for Sustainable Development, 17(2), 127-137. https://doi.org/10.1016/j.esd.2012.07.007 